\title{
Health effects of occupational exposure to static magnetic field in a chloralkali plant
}

\begin{abstract}
A cross-sectional study was conducted to determine if long-term exposure to static magnetic fields could be related to findings of medical examination. Health data was obtained for 20 workers who spent a major period of their working time in the magnetic field produced by direct current through large electric cells. The data was compared to that of control group of 21 workers. Intensity of magnetic flux density was measured in the Chloralkali plant and the TWA exposure to magnetic field was determined for each job classification. Maximum and minimum intensities were found to be 16.99 and $0.49 \mathrm{mT}$, respectively, which were well below the recommended level. Maximum TWA exposure to magnetic field was equal to $47.59 \mathrm{mT}$ that was less than the acceptable level. The results of clinical examinations and blood tests revealed that there was no significant difference between the two groups. The only effects which were found to be related to exposure to the magnetic field were nervousness and fatigue. Studying a larger sample size may contribute to detect any health effects of occupational exposure to static magnetic field in industrial settings.
\end{abstract}

Key words: Chloralkali plant, Occupational exposure, Static magnetic field

\section{INTRODUCTION}

Static magnetic fields are naturally present everywhere as the earth is surrounded by fields varying between 0.03 and $0.070 \mathrm{mT} .{ }^{[1]}$ Superimposed on the earth's magnetic field, there may also be man-made static magnetic fields. Certain industry processes use strong static magnetic fields usually created by rectified altering currents. Thus the workers, for instance, in aluminum production industries and at Chloralkali plants are exposed to static magnetic fields ranging from 4 to $50 \mathrm{mT}^{[2]}$

Although past research has shown that externally applied magnetic fields interact with biological systems to produce detectable changes, there are apparent inconsistencies and uncertainties in the findings. ${ }^{[3]}$ Studies on workers involved in the manufacture of permanent magnets in the former USSR indicated various subjective symptoms and functional disturbances including irritability, fatigue, headache, loss of appetite, bradycardia, tachycardia, decreased blood pressure, altered EEG, itching, burning, and numbness. ${ }^{[4]}$ However lack of any statistical analysis or assessment of the impact of physical or chemical hazards in the working environment significantly reduces the value of these reports. Epidemiological surveys in the USA have failed to reveal any significant health effects associated with longterm exposure to static magnetic fields. A study of the health data on 320 workers in mechanical plants using large electrolytic cells for chemical separation processes, where the average static field level in the work environment was $7.6 \mathrm{mT}$ and the maximum field was $14.6 \mathrm{mT}$, indicated slight changes in white blood cell picture in the exposed group compared to the controls. None of the observed changes in blood parameters considered indicative of a significant adverse effect associated with magnetic field exposure. ${ }^{[3]}$ Barregard et al. studied a worker cohort at a Chloralkali plant with exposure level of 4-29 mT and found that the observed and expected cancer incidence rates over 25 years were not significantly different. ${ }^{[5]}$

The amount of data available for use in health risk assessment associated with static magnetic field exposure is limited $^{[6]}$ and the available evidence from epidemiological studies is not sufficient to draw any conclusion about potential health effects of static magnetic field exposure. ${ }^{[2]}$ Therefore, conducting more epidemiological studies on exposed workers and investigating possible long-term

\section{A. Choobineh,} F. Amirzadeh Occupational Health Department, School of Health, Shiraz University of Medical Sciences, Shiraz, Iran

For correspondence: A. Choobineh, Department of Occupational Health Department, School of Health, University of Medical Sciences, Shiraz - 71645-111, Iran. E-mail: alrchoobin@sums.ac.ir

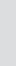
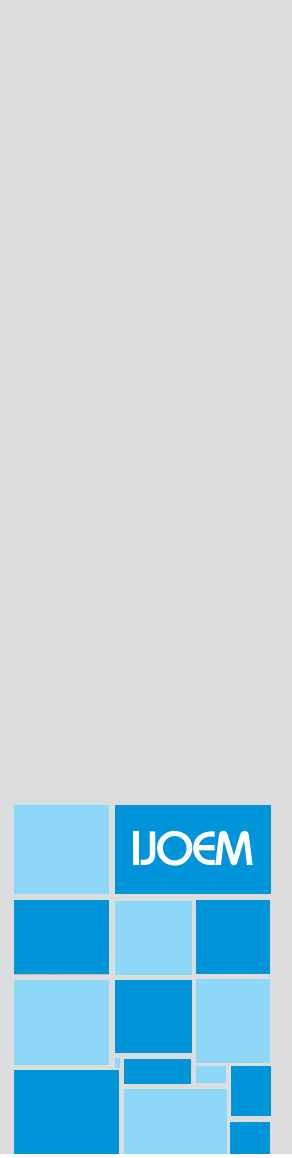
health effects of exposure to static magnetic fields is needed. Regarding this, the present study was conducted to assess further the health effects of occupational exposure to strong static magnetic field in a Chloralkali plant, in which highintensity direct current (DC) electrical current (110 kA) was used in industrial electrolytic processes. The main objectives of the study were:

Determination of the magnetic flux density in the plant.

- Determination of time-weighted average exposure of the workers to the magnetic flux.

- Investigation of the health effects of static magnetic field exposure among the workers.

\section{MATERIALS AND METHODS}

A cross-sectional study was conducted to determine if there were statistically significant differences in physiological and subjective parameters for groups of workers exposed to static magnetic field as compared to groups not so exposed. Health data were gathered during regularly scheduled physical examination done by the plant physician. Magnetic field density and time-weighted average exposures were measured by a Tesla-meter. The data was then statistically analyzed to determine if a relationship could be established between the medical data and the magnetic field exposure.

\section{Health data}

Health data was obtained for different medical parameters for each participant. This was furnished in the form of a medical questionnaire completed by the physician while performing the annually scheduled physical examination given to each employee. These examinations were performed over a period of 5 months. The medical questionnaire used in this study contained four types of data. The first type was related to demographic details of the participants. The second type of data was the objective determinations made by the physician (i.e., blood pressure, pulse rates, and cardiac irregular rhythm). The third type was the subjective response to questions asked by the physician including headache, nervousness, chest pain, fatigue, loss of appetite, dizziness, irritability, visual disturbances, anxiety, and sleeplessness. The fourth type of data was the results of laboratory studies including a complete blood count, electrocardiogram, and electroencephalogram.

\section{Study population}

The study population came from two different plants in a petrochemical company. The exposed group was workers from Chloralkali plant who spent a major portion of their working shift in static magnetic fields. The control group consisted of workers from perchlorin plant with no occupational exposure to magnetic field in their work. The exposed group consisted of 20 males from five diverse jobs. They were involved in the production of chlorine by electrolysis of $\mathrm{NaCl}$ in large mercury cells. In the electrolytic cells, high-intensity DC was used which created strong magnetic fields. The control group consisted of 21 males who were involved in the production of perchlorin. The control group was matched with the exposed group for age, job experience, weight, stature, smoking, daily working hours, and shift working. Personal characteristics of the participants are presented in [Table 1].

\section{Magnetic field measurements}

Spot magnetic flux density and time-weighted average exposure to the magnetic field were measured using the Tesla meter HI-3350 manufactured by Hollady factory, USA. Spot measurements were made in different locations of the Chloralkali plant, around the cells and in the control room at three heights (i.e., $30 \mathrm{~cm}$ for legs, $110 \mathrm{~cm}$ for abdomen and $160 \mathrm{~cm}$ for head) above the floor. Magnetic flux dosimetry was done through the whole shift for five different job tittles in the Chloralkali plant. Magnetic flux density was measured in the perchlorin plant as well.

\section{RESULTS}

\section{Medical questionnaire}

[Table 2] presents the results of clinical and paraclinincal examinations in the exposed and the control groups. Statistical analyses showed no significant difference between the two groups $(P>0.05)$.

[Tables 3 and 4] show the results of cardiac factors extracted from electrocardiograms in the two groups. No significant difference was observed between the two groups $(P>0.05)$. The results of EEG revealed that four workers had abnormal electroencephalogram, two from the Chloralkali and two from the perchlorine plants. This shows that no difference exists from EEG point of view between the two groups.

[Table 5] demonstrates the frequency of reported subjective symptoms among the exposed and the control groups. Statistical analyses revealed that in spite of higher frequency rate of subjective symptoms reported by the exposed workers,

Table 1: Personal details of the exposed $(n=20)$ and the control $(n=21)$ groups studied

\begin{tabular}{lll}
\hline Details & \multicolumn{2}{c}{ Group } \\
& Exposed & Control \\
\hline Age (years) & $\mathrm{M}=32$ & $\mathrm{M}=31.2$ \\
Weight $(\mathrm{kg})$ & $\mathrm{SD}=4.8$ & $\mathrm{SD}=5.1$ \\
& $\mathrm{M}=66$ & $\mathrm{M}=66.52$ \\
Job experience in the current plant (years) & $\mathrm{SD}=9.6$ & $\mathrm{SD}=8.9$ \\
& $\mathrm{M}=6.25$ & $\mathrm{M}=5.9$ \\
Stature & $\mathrm{M}=1.4$ & $\mathrm{SD}=1.3$ \\
& $\mathrm{SD}=12.8$ & $\mathrm{M}=170.3$ \\
Smoking (\%) & $\mathrm{S}=5.7$ \\
& $\mathrm{Nos}=20 \%$ & $\mathrm{Yes}=24 \%$ \\
& & $\mathrm{No}=76 \%$ \\
\hline
\end{tabular}


Table 2: Mean and standard deviation values of medical variables studied in the exposed $(n=20)$ and the control ( $n=21)$ groups

\begin{tabular}{lllll}
\hline & \multicolumn{4}{c}{ Group } \\
& \multicolumn{2}{c}{ Exposed } & \multicolumn{2}{c}{ Control } \\
& Mean & SD & Mean & SD \\
\hline Pulse rate (beats/min) & 64.8 & 9.8 & 61 & 7.1 \\
Systolic blood pressure (mmHg) & 112.25 & 12.9 & 112.38 & 10.9 \\
Diastolic blood pressure (mmHg) & 71.5 & 7.3 & 73.8 & 8.8 \\
Hematocrit (\%) & 49.05 & 4.1 & 48.43 & 4.1 \\
E.S.R. (mm) & 2.58 & 1.7 & 3.14 & 2.1 \\
Hemoglobin & 15.55 & 0.9 & 15.2 & 0.9 \\
Platelet count * & 242100 & 92170 & 191904 & 61936 \\
White blood cell count * & 8442 & 2630 & 7261 & 2192 \\
Monocyte (\%) & 0.75 & - & 0.76 & - \\
Lymphocyte (\%) & 42 & 11 & 41.05 & 11.5 \\
Basophile & 0.1 & - & 0.0 & - \\
Eosinophil & 3.2 & 2.33 & 3.86 & 2.97 \\
Neutrophil & 52 & 10.9 & 54.57 & 12.25 \\
\hline
\end{tabular}

* Statistical analysis was performed on the natural logarithmic value

Table 3: Mean and standard deviation values of PR, ORS, and QS factors in the exposed $(n=20)$ and the control $(n=21)$ groups

\begin{tabular}{lllll}
\hline Cardiac factors & \multicolumn{3}{c}{ Group } \\
& \multicolumn{2}{c}{ Exposed } & \multicolumn{2}{c}{ Control } \\
& Mean & SD & Mean & SD \\
\hline PR $(\mathrm{ms})$ & 178.9 & 25.2 & 206.2 & 28.8 \\
ORS $(\mathrm{ms})$ & 71.1 & 10.23 & 68.15 & 12 \\
OT $(\mathrm{ms})$ & 367.2 & 47.9 & 318.5 & 23.7 \\
\hline
\end{tabular}

Table 4: Frequency of abnormality in ST and T-wave among the exposed and the control groups

\begin{tabular}{lcccccc}
\hline Cardiac variables & \multicolumn{5}{c}{ Group } \\
& Normal & $\begin{array}{c}\text { Exposed } \\
\text { Abnormal }\end{array}$ & Total & Normal & $\begin{array}{c}\text { Control } \\
\text { Abnormal }\end{array}$ & Total \\
\hline ST & 14 & 4 & 18 & 10 & 8 & 18 \\
T-wave & 16 & 5 & 21 & 13 & 8 & 21 \\
\hline
\end{tabular}

Table 5: Frequency rate of subjective symptoms reported by the exposed $(n=20)$ and the control $(n=21)$ groups

\begin{tabular}{lcc}
\hline Subjective symptom & \multicolumn{2}{c}{ Group } \\
& Exposed (\%) & Control (\%) \\
\hline Headache & 40 & 19 \\
Nervousness & 75 & 29 \\
Chest pain & 10 & 14 \\
Fatigue & 65 & 33 \\
Loss of appetite & 20 & 14 \\
Dizziness & 35 & 14 \\
Irritability & 15 & 5 \\
Visual disturbances & 30 & 10 \\
Numbness & 50 & 29 \\
Sleeplessness & 35 & 19 \\
\hline
\end{tabular}

no significant difference was observed for most variables. Statistical analyses demonstrated that only frequency rates of nervousness and fatigue were higher in the exposed group as compared to the control group $(P<0.01)$.

\section{Magnetic field measurements and dosimetry}

The minimum and the maximum magnetic flux density in the cell room area were found to be 0.42 and $16.99 \mathrm{mT}$, respectively. In all cases, magnetic field at $30 \mathrm{~cm}$ above the floor had the highest value as compared to the heights of 110 and $160 \mathrm{~cm}$. In general, measurements indicated that magnetic flux density in the southern part of the Chloralkali plant where the transformer and the rectifier were located, was greater than in the northern side of the plant. In the control room, the minimum and the maximum magnetic flux density were 0.34 and $3.71 \mathrm{mT}$, respectively.

Magnetic flux density was founded to be very close to zero in the perchlorine plant from where the control workers came. Time-weighted average exposure level to static magnetic field for the five job titles studied in the Chloralkali plant is presented in Table 6. As shown in Table 6, the cell coordinator has the highest level of exposure.

\section{DISCUSSION}

The results demonstrated that the frequency rate of nervousness and physical fatigue were higher among the exposed group $(P<0.01)$. It is in agreement with the results reported ${ }^{[3]}$ These two subjective symptoms could, therefore, be related to static magnetic field exposure.

The results of clinical examinations and blood tests revealed that there was no significant difference between the two groups. Cardiac and mental activity followed the same pattern in the both the groups and no significant difference was observed.

Fields measurements indicated that static magnetic flux density, in all locations of the Chloralkali plant was well below the ceiling value (2T) recommended by ACGIH. ${ }^{[7]}$ On the basis of the measurements, the flux density lowered with the increase of height from the floor. This was because of the distance from the sources (cells), which were located on the floor. The difference between the magnetic flux density at 30 and $160 \mathrm{~cm}$ was found to be $20 \%$ of the value measured at $30 \mathrm{~cm}$ height. This could result in the reduction of the effects of static magnetic flux on the heart and brain known as sensitive organs to magnetic fields.

Table 6: Time-weighted average exposure level to magnetic field and measurement time for the five job titles studied

\begin{tabular}{lcc}
\hline Occupational title & $\begin{array}{l}\text { Measuring time } \\
\text { (h/min/s) }\end{array}$ & $\begin{array}{l}\text { Magnetic flux density } \\
\text { (mT) }\end{array}$ \\
\hline Shift supervisor & $8 / 11 / 18$ & 21.25 \\
Board man & $7 / 55 / 30$ & 17.56 \\
Cell room operator & $7 / 58 / 18$ & 26.26 \\
Cells coordinator & $8 / 05 / 14$ & 47.59 \\
Cell room worker & $8 / 15 / 29$ & 42.78 \\
\hline
\end{tabular}


Dosimetry performed, demonstrated that 8-hour TWA exposures of the workers in the Chloralkali plant did not exceed the TLV-TWA value recommended by ACGIH for the whole body $(60 \mathrm{mT}){ }^{\left[{ }^{7]}\right.}$ The highest TWA exposure occurred for the cells coordinator, who spent most of his working time near the cells. The board man who worked in the control room had the lowest TWA exposure level.

\section{CONCLUSION}

The data obtained in this study is in basic agreement with the results reported by Marsh et al..$^{[3]}$ and in disagreement with the results of Vyalov's study. ${ }^{[4]}$ None of the medical parameters studied were found to be dependant on magnetic field exposure at the Chloralkali plant. The only subjective effects found to be associated with exposure to the magnetic field were nervousness and fatigue. Generally, both the groups were found to be in good health. The effects, which were found, are slight and any future studies must be highly refined or must have a large sample size in order to detect them.

\section{REFERENCES}

1. Stuchly MA. Human exposure to static and time-varying magnetic fields. Health Physics 1986;51:215-25.

2. Feychting M. Health effects of static magnetic fields-areview of the epidemiological evidence. Prog Biophys Mol Biol 2005;87:241-6.

3. Marsh JL, Armstrong TJ, Jacobson AP, Smith RG. Health effect of occupational exposure to steady magnetic fields. Am Ind Hyg Assoc J 1982;43:387-94.

4. World Health Organization. Environmental health criteria 69: Magnetic fields. WHO; Geneva, Switzerland; 1987.

5. Barregard L, Jarvholm B, Ungethum E. Cancer among workers exposed to strong static magnetic fields. Lancet 1985;2:892.

6. Roy C and Repacholi M. Electromagnetic fields and health: A WHO perspective. http://www.world-aluminium.org/news/montreal/roy.htm. Dec, 6, 2004.

7. American Conference of Governmental Hygienists. Threshold limit values for chemical substances and physical agents and biological exposure indices. Cincinnati: ACGIH; 2003.

\title{
ANNOUNCEMENT
}

\section{Medicon 2005}

\section{0th National Conference of Indian Medical Association} Tuesday 27th to 29th December, 2005

\author{
Venue: Chennai Trade Centre, Mount ponamallee Road, \\ Nandampakkam, Chennai - 600089.
}

Scientific Convenor : Dr. S. Chandrasekharan,

No. 4, Jambulingam street, Nungambakkam, Chennai, 600,034.

Tel: 91 - 44 - 28275832 / 28312946, Mobile: 0- 9840015023

E-mail: schan2004@rediffmail.com

Registration: Dr. T. Sadagopan, Organising Secretary, No. 4, Jambulingam street, Nungambakkam, Chennai, 600,034.

Tel: 91 - 44 - 28275832 / 28312946, Mobile: 0- 9840015023

E-mail: schan2004@rediffmail.com 